\title{
OVIPOSITION DETERRENCE AND OVICIDAL ACTIVITY OF BIRBIRA (Melletia furrgunia) ON DIAMONDBACK MOTH (Plutella xylostella) (LEPIDOPTERA: PLUTELLIDAE)
}

\author{
Adem Nega ${ }^{1+}$
} Bayeh Mulatu ${ }^{2}$

\author{
'College of Natural Science, Department of Biology, Debre Markos \\ University, Ethiopia. \\ Email:adem.nega1@gmail.com Tel: +251910107711 \\ ${ }^{2}$ Holetta Agricultural Research Center3, Holetta, Ethiopia. \\ Email: bayeh65@yahoo.com Tel: +251913204797
}

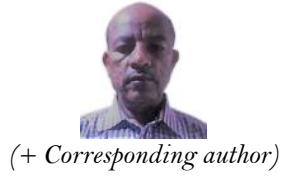

\section{Article History}

Received: 16 August 2021 Revised: 29 September 2021 Accepted: 22 November 2021 Published: 28 December 2021

\section{Keywords}

Efficacy

Extracts

Mortality

Ovicidal

Oviposition

Solvent.

\section{ABSTRACT}

The efficacy of different polar and non-polar solvent extracts of Birbira, Melletia furrginea (Hochst.) Baker tree seeds namely: Water, Acetic acid, Acetone, Chloroform, Toluene, and Hexane at different rates were evaluated on Diamondback moth, Plutella xylostella L. oviposition and egg mortality under laboratory conditions. The leaf dipping method was used to run both assays. In the assay, full Oviposition deterrence was recorded at the higher rates of polar solvent extracts. Significantly higher egg unhatchability was recorded only at the higher rates for non-polar extracts. Eggs mortality caused by extracts with Water and Acetone was very high, and have much smaller LC50 values. In contrast, LC50 was higher for the other extracts. However, there was a constant increase in the percent kill of egg mass with the increase in the extract concentration. From this study, it is evident that M. furrgunia extracts with different solvents possess significant oviposition deterrence and ovicidal effect on $\mathrm{P}$. xylostella.

Contribution/Originality: The study was carried out on the Evaluation of solvent extracts of Melletia furrgunia against Diamondback Moth, Plutella xylostella. The paper's primary contribution is finding that M. furrgunia extracts with different solvents possess significant oviposition deterrence and ovicidal effect against P. xylostella

\section{INTRODUCTION}

The Diamondback Moth, Plutella xylostella (Lepidoptera: Plutellidae) is the most important destructive insect pest of crucifers throughout the world including Ethiopia, Ayalew and Ogol [1]; Charleston [2]; Liang, et al. [3]. Damage and loss due to feeding by $P$. xylostella larvae is estimated to billions of dollars each year in the world, with comparable losses in many other developed countries. The loss is even more staggering in the developing countries mainly in Asia and Africa, FAO [4]; Gashawbeza [5].

Control of this pest largely depends on the use of synthetic insecticides. But extensive use of synthetic insecticides resulted in the development of resistance of this pest [6]; [7]. In addition, chemicals can be environmentally disruptive, eliminate beneficial insects, being direct toxicity to non-target organisms and accumulation of residues in the harvested produces [8].

Under such conditions the uses of botanical insecticides have been touted as attractive alternatives to synthetic insecticides as it causes adverse effect on the development and reproduction of pest insects. They are eco-friendly, economic, effective, safe to prepare, biodegradable, nontoxic and non-pathogenic to animals and humans as well. 
Considering these facts to manage the pests, the present study has therefore been undertaking to study the efficacy of $M$. furrginea seed kernel extracts obtained using solvents of different polarity on $P$. xylostella oviposition deterrence and ovicidal effects under laboratory condition. So that information thus gathered may be utilized for the management of this pest under field condition.

\section{MATERIALS AND METHODS}

Physiologically matured pods of M. ferruginea collected from the premises of Holeta Agricultural Research Centre (HARC) and neighbouring areas. Pods brought to the insectary at HARC and put aside for few days to dry. Seeds removed from the pods and seed coats split to remove the cotyledons. The cotyledons were ground to powder using mortar and pestle under shady condition. The powder kept in a sealed polythene bag in a refrigerator at $4^{\circ} \mathrm{c}$ until used for its crude extractions using different solvents. Different polar and non-polar solvents (de-ionized water, acetic acid, acetone, chloroform, toluene and hexane with the polarity index of 9.0, 6.2, 5.1, 4.1, 2.4, and 0.1, respectively) used for the extraction of the powder following the procedures used by Mulatu [9]. Six samples of 50 gm of powder weighed separately for crude extractions. Each sample mixed with $100 \mathrm{ml}$ solvent in separate flasks. The mixtures stirred continuously for 15 minutes using a magnetic stirrer at room temperature until homogenous solutions formed and then left to stand.

\subsection{Oviposition Deterrence Bioassay}

To study the oviposition deterrence effect of different solvent extracts, excised leaves of cabbage dipped for $1 \mathrm{hr}$, dislodge the liquid and the cut end of each treated leaf covered with tap water wetted cotton ball. The treated leaves then put into separate Petri dishes, transferred into an oviposition cage and arranged in a completely randomized way within the cage.

The Petri dishes were left open in the cages and 3 pairs of newly emerged naive adults of P. xylostella were introduce and provided with 10\% sugar solution soaked in cotton balls. The total numbers of treatments were 48 , with 3 replications. A total of 48 adults were run per treatment in the assay. All the cages covered with cloth to produce dark condition for the adults. The introduced adults allowed mating and ovipositing for 3 days and all the adults removed afterwards. The number of laid eggs checked and counted on leaves and in the inner surface of the cages after $72 \mathrm{hrs}$.

\subsection{Ovicidal Bioassay}

To study the ovicidal effect of different solvent extracts, 40 fresh untreated excised cabbage leaves were taken from the greenhouse and put in a bigger cage. Then after 5 pairs of newly emerged naive adults were introduced in a cage containing cabbage leaves and allowed to mate and oviposit. Mating is expected to occur soon after emergence from the cocoon.

All the adults removed afterwards after the oviposition period was over (i.e. after 72 hours). Eggs that were laid on each leaves in each mica cages were counted and recorded. Eggs that were counted up to 25 on each leaf recorded and labelled on pieces of paper with pencil and pinned to the leaf stalk with small pins. Leaves, which contain 25 eggs for each concentration, dipped for 30 seconds into each extracts of the serial concentrations, prepared in the bowls. After 30 seconds, eggs that received same treatment were taken out, dried on paper bowel, placed into each transparent square plastic cage and kept at room conditions until any egg hatchability is completed or died. Each experiment replicated five times along with appropriate control. The hatch rates were assessed 48 hours after treatment by the following formula.

$\%$ of eggs mortality $=\underline{\text { Number of hatched larvae }} \times 100$

Total number of eggs 


\subsection{Statistical Analysis}

All the experiments laid in a completely randomized design (CRD). For the data to all the extracts one-way ANOVA [10] was used. Mean comparisons were conducted using Tukey Kramer honest significance test, and P value was set at $5 \%$ probability level.

\section{RESULT}

P. xylostella adults were inhibited to oviposit on cabbage leaves treated with Water and Acetone solvent extracts at the higher rates Table 1 . The number of eggs laid by female P. xylostella on treated and the control leaves did not differ significantly at the lowest concentrations $(0.2 \% \mathrm{w} / \mathrm{v})$ of Toluene extract.

No oviposition deterrence observed in the extract of Acetic acid at all the rates and at the lower rates of Toluene and Hexane. Number of eggs laid became decreasing in the extracts of Chloroform as the rate increases and no eggs were laid at the higher rate (1.4). The oviposition deterrence effects of the other extracts were similar and showed increased deterrence as concentration increases Table 1.

Table-1. Mean $( \pm \mathrm{SE})$ eggs laid by adult, P. xylostella on cabbage leaves treated with different solvent extracts of M. furrginea seed powder.

\begin{tabular}{c|c|c|c|c|c|c}
\hline Rates & Water & Acetic acid & Acetone & Chloroform & Toluene & Hexane \\
\hline 0 & $8.00 \pm 1.87 \mathrm{Ba}$ & $8.00 \pm 3.11 \mathrm{Bb}$ & $8.60 \pm 1.86 \mathrm{Ba}$ & $9.00 \pm 4.15 \mathrm{Aa}$ & $9.80 \pm 4.58 \mathrm{Aa}$ & $10.80 \pm 1.83 \mathrm{Aa}$ \\
\hline 0.2 & $1.80 \pm 0.58 \mathrm{~Eb}$ & $10.40 \pm 1.32 \mathrm{Ab}$ & $4.80 \pm 0.86 \mathrm{Db}$ & $6.60 \pm 1.43 \mathrm{Bb}$ & $10.60 \pm 2.85 \mathrm{Aa}$ & $7.60 \pm 1.57 \mathrm{Bc}$ \\
\hline 0.4 & $0.80 \pm 0.20 \mathrm{Ec}$ & $6.00 \pm 5.02 \mathrm{Ac}$ & $1.00 \pm 0.44 \mathrm{Dc}$ & $2.00 \pm 1.14 \mathrm{Dc}$ & $7.80 \pm 2.31 \mathrm{Ab}$ & $8.60 \pm 4.27 \mathrm{Ab}$ \\
\hline 0.6 & $1.2 \pm 0.73 \mathrm{~Eb}$ & $10.20 \pm 1.27 \mathrm{Ab}$ & $2.60 \pm 2.11 \mathrm{Db}$ & $5.00 \pm 1.64 \mathrm{Cb}$ & $7.40 \pm 1.86 \mathrm{Bb}$ & $5.40 \pm 1.80 \mathrm{Cd}$ \\
\hline 0.8 & $0.40 \pm 0.24 \mathrm{Dc}$ & $11.60 \pm 4.30 \mathrm{Aa}$ & $0.80 \pm 0.37 \mathrm{Dcd}$ & $1.60 \pm 0.87 \mathrm{Cd}$ & $5.60 \pm 2.67 \mathrm{Bb}$ & $4.60 \pm 1.50 \mathrm{Be}$ \\
\hline 1.0 & $0.0 \pm 0.00 \mathrm{Ec}$ & $9.20 \pm 4.20 \mathrm{Ab}$ & $0.20 \pm 0.734 \mathrm{Dc}$ & $0.00 \pm 0.00 \mathrm{Ee}$ & $2.00 \pm 1.04 \mathrm{Cd}$ & $4.40 \pm 1.56 \mathrm{Be}$ \\
\hline 1.2 & $0.2 \pm 0.24 \mathrm{Cc}$ & $7.00 \pm 0.70 \mathrm{Ac}$ & $0.40 \pm 0.40 \mathrm{Dd}$ & $2.00 \pm 1.26 \mathrm{Cc}$ & $4.20 \pm 1.35 \mathrm{Bc}$ & $4.80 \pm 0.96 \mathrm{Be}$ \\
\hline 1.4 & $0.0 \pm 0.00 \mathrm{Cc}$ & $4.60 \pm 2.29 \mathrm{Ad}$ & $0.00 \pm 0.00 \mathrm{Ce}$ & $0.00 \pm 0.00 \mathrm{Ce}$ & $2.20 \pm 2.66 \mathrm{Bd}$ & $2.00 \pm 1.09 \mathrm{Bf}$ \\
\hline Note: Means followed by the same letter (lowercase) within a column and (uppercase) within a row are not significantly different at P=0.05 $[10 \beth$.
\end{tabular}

Number of eggs laid on the inner surface of the Petri dishes within the Cages at different rates and different solvent extracts of M. furrginea were presented in Table 2. On comparing different extracts and rates, very small number of eggs was deposited in the inner surface of the petri dish at the lower rates of the extracts of Water, Acetone and Chloroform. However, No eggs were deposited at the higher rates of these extracts. In contrast to this, number eggs deposited were higher in all the rates of Hexane and at the lower rates of Toluene extracts. Significant numbers of eggs were deposited on the inner surface of the cages for all the rates of Acetic acid.

Table-2. Number of eggs laid on the inner surface of the Petri dishes within the Cages at different rates and different solvent extracts of M. furrginea.

\begin{tabular}{c|c|c|c|c|c|c}
\hline Rates & Water & Acetic acid & Acetone & Chloroform & Toluene & Hexane \\
\hline 0 & 13 & 8 & 11 & 16 & 20 & 18 \\
\hline 0.2 & - & 11 & 3 & 2 & 20 & 20 \\
\hline 0.4 & 3 & 2 & - & - & 2 & 5 \\
\hline 0.6 & 6 & - & 10 & 4 & -11 & 10 \\
\hline 0.8 & 4 & 9 & - & - & 5 & - \\
\hline 1.0 & - & 7 & - & 3 & 6 & 16 \\
\hline 1.2 & - & 3 & - & - & 9 \\
\hline 1.4 & - & 8 & - & &
\end{tabular}

Figure 1 shows the effect of different solvent extracts of $M$. furrginea on $P$. xylostella eggs hatchability at different concentration. Percentage of eggs un-hatchability was higher at the higher rates of Water followed by Acetone and Chloroform. These insecticides were also better than the others even in the lowest applied dose. Percentage of eggs un-hatchability increases as the rates increases. There was no significant difference in the percentage of eggs un-hatchability between the control, Acetic acid and Toluene. 


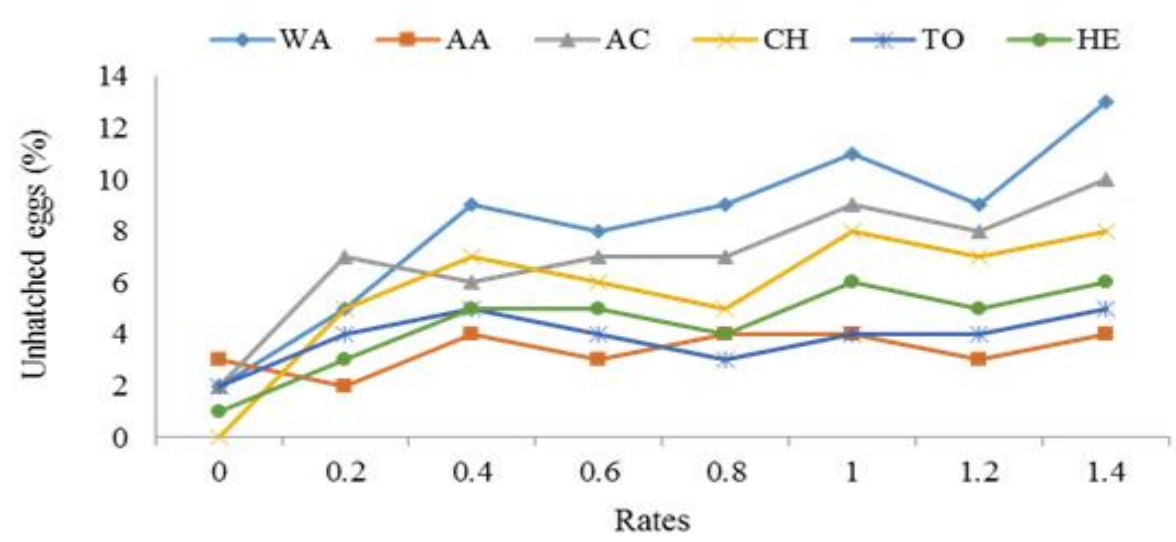

Figure-1. Number of eggs un-hatchability of P. xylostella on cabbage leaves treated with different solvent extracts of $M$. furrginea.

\subsection{LC50 of Different Solvent Extracts of M. Furrginea against P. Xylostella Eggs}

Significant lethal effects of the solvent extracts on eggs, found five days after treatment compared with the controls were presented in Table 3. Water was the most toxic to P. xylostella eggs followed by Acetone and Chloroform. On comparing the efficacy of different solvent extracts, Water and Acetone extracts were found to be the most effective in ovicidal activity with the LC50 value of 0.23 and 0.30 respectively. Chloroform extracted $M$. furrginea revealed moderately ovicidal activity with the LC50 value of $0.51 \mathrm{mg} / \mathrm{m} 3$. Hexane and Toluene solvent extracts of M. furrginea showed the least ovicidal effect. However, acetic acid extracted M.furrginea had no effect on the hatched eggs.

Table-3. LC 50 M. furrginea extracts of different solvents against P. xylosttela Eggs.

\begin{tabular}{|c|c|c|c|c|}
\hline Extract type & $\mathrm{LC}_{50}\left(\mathrm{mg} / \mathrm{m}^{3}\right)$ & 95\% confidence limits lower \& upper limits & Intercept & St. error \\
\hline Water & 0.2366 & $0.0797,0.4587$ & 0.0511 & 0.0506 \\
\hline Acetic acid & 1.3163 & $0.6275,3.2819$ & 0.0976 & 0.0495 \\
\hline Acetone & 0.3065 & $0.2358,0.9666$ & 0.2415 & 0.0492 \\
\hline Chloroform & 0.5128 & $0.1204,0.5940$ & 0.4128 & 0.0501 \\
\hline Toluene & 0.5340 & $0.8358,2.2857$ & 0.1699 & 0.0500 \\
\hline Hexane & 0.5899 & $0.2688,1.0948$ & 0.2034 & 0.0495 \\
\hline
\end{tabular}
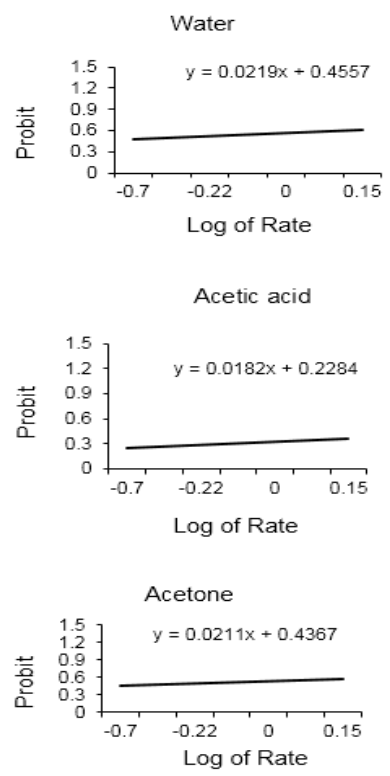
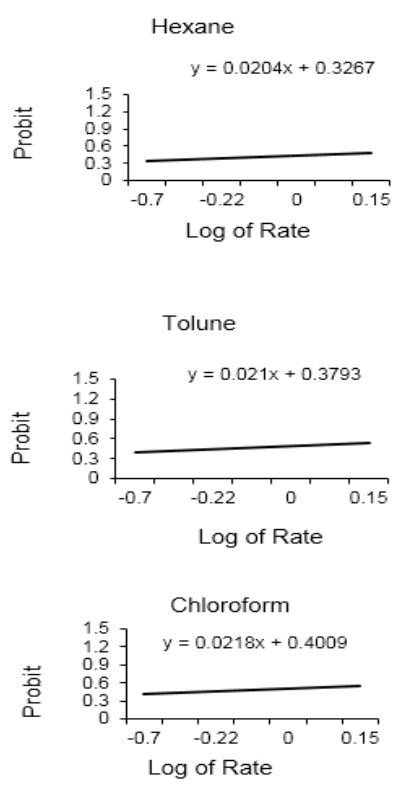

Figure-2. Probit mortality graphs of different solvent extracts of M. furrginea against P. xylostella Eggs. 


\subsection{Percentage of Different Solvent Extracts of M. Furrginea against P. Xylostella Eggs mortality}

Figure 2 shows the toxicity of different solvent extracts of $M$. furrginea against $P$. xylostella eggs at different concentration. Percentage of eggs mortality was higher at Water extracts followed by Acetone and Chloroform. These insecticides were also better than the others even in the lowest applied dose. Mortality of M. furrginea eggs increases as the rates increases in these treatments. However there was no significant difference in the percentage of eggs mortality between the control, Acetic acid and Toluene.

\section{DISCUSSION}

In the present study solvent extracts of $M$. ferruginea against $P$. xylostella ovipostion activity and ovicidal effects were effective. P. xylostella adults were inhibited to oviposit on cabbage leaves treated with Water and Acetone solvent seed extracts at the higher rates. The deterrence oviposition of $P$. xylostella adults by these solvent extracts suggesting that the deterrent effect of the $M$. ferruginea seed extracted with Water and Acetone is probably due to the rotenone content of the seeds and the solvent type in extracting the bioactive compounds.

Rotenoid compounds have previously been evaluated largely as insect toxicants and the doses of this active compounds used have been required to cause high levels of mortality on target pests [5]. Similar to this result, recent findings showed that oviposition by a species of beetle, Monochamus alternates and Callosobruchus maculatus was deterred by rotenone [11]. Oviposition deterrence was not observed in the extract of Acetic acid and at the lower rates of Toluene and Hexane. Acetic acid solvent extracts showed no deterrence effect on P. xylostella oviposition at the lower rates of the extracts suggesting the bioactive present in the botanical may not be extracted efficiently by the Acetic acid solvent. In our study, it is possible to see that the deterrence of oviposition can be explained by both the effectiveness of the solvent to the extract, the bioactive compounds and the presence of chemical compounds primarily (Rotenone) contained in the extracts.

Very small numbers of eggs were deposited in the inner surface of the petri dish at the lower rates of the extracts of Water, Acetone and Chloroform. However, No eggs were deposited at the higher rates of these extracts. This suggested that there might have been sufficiently large amount of the active compounds released over $72 \mathrm{hrs}$ and deterred the gravid females from laying their eggs even on the inner walls of the Petri dishes within the cages. Numbers of eggs deposited on the inner surface of the Petri dishes within the cages were higher for all the rates of Acetic acid, Toluene and Hexane extracts. However, numbers of eggs deposited were insignificant as the rates of these extracts increases. What is very interesting to notice here is that the deposition of eggs on the inside surface of the cages decreased significantly like on the leaves with the increasing rates of application of the extract and no eggs were deposited away from the leaves at $1.4 \mathrm{mg} / \mathrm{ml}$. This shows that the higher rates of crude extract with polar solvents completely arrested the oviposition response by $P$. xylostella adults.

Number of $P$. xylostella eggs un-hatchability on cabbage leaves treated with different solvent extracts of $M$. furrginea increases as concentration increases. This fact was recorded by Liu, et al. [12] The highest number of unhatched eggs was recorded from Water followed by Acetone and Chloroform. In all the other extracts egg hatching was significantly lower at the tested concentration increases. This was found to be because of the ovicidal effects of the solvent extraction increases as the rate increases. However, increasing the extract concentration had no effect in eggs hatching of the solvent extracts of Acetic acid and Toluene.

The ovicidal effect indicated here in this study might be due to a contact toxicity of these solvent extracts. Similar to this result [13] reported lufenuron has ovicidal activity on Lobesia botrana (Lepidoptera: Tortricidae) in contact treatment. Regarding the effect of solvent extracts of $M$. furrginea on eggs of $P$. xylostella the present study showed that water extracts of M. furrginea has best contact toxicity followed by Acetone on eggs compared to the other tested solvent extracts. One possible explanation for this could be these solvent extracts might have high active ingredient (a.i) than the other botanical insecticides as water is more efficient for extracting these compounds than the other solvents. 
In the present study, although Hexane had an ovicidal effect on P. xylostella, it was not as good as the effect of Chloroform. This could be due to difference in their respective extracting capability. Microscopic examinations of the un-hatched eggs revealed that majority of the eggs killed at the very early stages of development in Water and Acetone extracts. It also found that some neonates died before they hatched from the eggs, implying that the insecticides on the egg surface were toxic to the neonates when they contacted with these materials while hatching.

\section{CONCLUSION}

It is concluded that among the Birbira, M. furrginea seed extracts with different solvents Water and Acetone extracts were deterred P. xylostella adults from laying eggs. All the other solvent extracts were found effective in a concentration-dependent manner. Eggs hatchability was significantly affected at the higher concentration of all the solvent extracts except Acetic acid. Similar to the higher dose treatments Water extracted M. furrginea caused the highest and excellent egg mortality followed by Acetone. Among the other solvent extracts examined water and Acetone extracts had the greatest efficacy on P. xylostella oviposition and eggs mortality. Hence, the use of water and Acetone extracts of $M$. furrginea is an excellent alternative to prevent damage to vegetables caused by $P$. xylostella.

Funding: This study received no specific financial support.

Competing Interests: The authors declare that they have no competing interests.

Acknowledgement: The authors are thankful to Addis Ababa University for financial support

and Holetta Agricultural Research Centre (HARC) and its staff for their support and Laboratory facilities.

\section{REFERENCES}

[1] G. Ayalew and C. Ogol, "Occurrence of the diamondback moth (Plutella xylostella L.) and its parasitoids in Ethiopia: influence of geographical region and agronomic traits," Journal of Applied Entomology, vol. 130, pp. 343-348, 2006.Available at: https://doi.org/10.1111/j.1439-0418.2006.01078.x.

[2] D. S. Charleston, "Integrating biological control and botanical pesticides for management of Plutella xylostella L.)," MSc Thesis, Wageningen University, Wageningen, Netherlands, 2004.

[3] G.-M. Liang, W. Chen, and T.-X. Liu, "Effects of three neem-based insecticides on diamondback moth (Lepidoptera: Plutellidae)," Crop Protection, vol. 22, pp. 333-340, 2003.Available at: https://doi.org/10.1016/s0261-2 194(02)00175-8.

[4] FAO, Inter country program for the development and application of IPM in vegetable growing in south and southeast Africa. Vientiane, Lao: FAO (Food and Agricultural Organization), Pesticide in cabbage IPM: An Ecological Guide, 2000.

[5] A. Gashawbeza, "Comparison of yield loss on cabbage from Diamondback moth, Plutella xylostella L.(Lepidoptera: Plutellidae) using two insecticides," Crop Protection, vol. 25, pp. 915-919, 2006.Available at: https://doi.org/10.1016/j.cropro.2005.12.001.

[6] H. Oouchi, "Insecticidal properties of a juvenoid, pyriproxyfen, on all life stages of the diamondback moth, Plutella xylostella (Lepidoptera: Yponomeutidae)," Applied Entomology and Zoology, vol. 40, pp. 145-149, 2005.Available at: https://doi.org/10.1303/aez.2005.145.

[7] S. R. Belmain, B. A. Amoah, S. P. Nyirenda, J. F. Kamanula, and P. C. Stevenson, "Highly variable insect control efficacy of Tephrosia vogelii chemotypes," Journal of Agricultural and Food Chemistry, vol. 60, pp. 10055-10063, 2012.Available at: https://doi.org/10.1021/jf3032217.

[8] N. Ebrahimi, A. A. Talebi, and Y. Fathipour, "Demographic parameters of the Diamondback moth, Plutella xylostella (Lepidoptera: Plutellidae) on five rapeseed cultivars Tehran," Iranian Journal Entomological, vol. 28, pp. 49-59, 2009.

[9] B. Mulatu, "Contact bioassay of an endemic plant to Ethiopia on three aphid species," Ethiopian Journal of Biological Sciences, vol. 6, pp. 51-62, 2007.Available at: https://doi.org/10.4314/ejbs.v6i1.39040.

[10] JMP®, "Version 5.1 JMP: The statistical discovery software," ed Cary, NC: SAS Institute Inc, 2003, pp. $1989-2021$. 
[11] A. Basukriadi and M. W. Richard, "Oviposition deterrent activities of pachyrhizus erosus seed extract and other natural products on Plutella xylostella (Lepidoptera: Plutellidae)," Journal of Insect Science, vol. 14, pp. 3-4, 2014.Available at: https://doi.org/10.1093/jisesa/ieu 106.

[12] T.-X. Liu, A. N. Sparks Jr, W. Chen, G.-M. Liang, and C. Brister, "Toxicity, persistence, and efficacy of indoxacarb on cabbage looper (Lepidoptera: Noctuidae) on cabbage," Journal of Economic Entomology, vol. 95, pp. 360-367, 2002.Available at: https://doi.org/10.1603/0022-0493-95.2.360.

[13] F. Sáenz-de-Cabezón, E. Martínez-Villar, F. Moreno, V. Marco, and I. Pérez-Moreno, "Influence of sublethal exposure to triflumuron on the biological performance of Tetranychus urticae Koch (Acari: Tetranychidae)," Spanish Journal of Agricultural Research, vol. 4, pp. 167-172, 2006.Available at: https://doi.org/10.5424/sjar/2006042-188.

Views and opinions expressed in this article are the views and opinions of the author(s), International Research Journal of Insect Sciences shall not be responsible or answerable for any loss, damage or liability etc. caused in relation to/arising out of the use of the content. 